\title{
Uso de óleos essenciais in natura e ozonizados no controle in vitro de Trichophyton mentagrophytes
}

\author{
Use of in natura and ozonated essential oils in the in vitro control of Trichophyton mentagrophytes \\ Uso de aceites esenciales frescos y ozonizados en el control in vitro de Trichophyton mentagrophytes
}

Recebido: 15/12/2020 | Revisado: 24/12/2020 | Aceito: 28/12/2020 | Publicado: 03/01/2021

\author{
Joelma Evelin Pereira Kume \\ ORCID: https://orcid.org/0000-0003-3486-7633 \\ Universidade Brasil, Brasil \\ E-mail: joelma.evelin@gmail.com \\ Roberto Andreani Junior \\ ORCID: https://orcid.org/0000-0002-0290-3356 \\ Universidade Brasil, Brasil \\ E-mail: robertoandreani@uol.com.br \\ Marilisa Flavia Pereira Di-Tanno \\ ORCID: https://orcid.org/0000-0003-4137-7499 \\ Estadual de Educação Tecnológica Paula Souza, Brasil \\ E-mail: mditanno@hotmail.com \\ Dora Inés Kozusny-Andreani \\ ORCID: https://orcid.org/0000-0003-3579-6419 \\ Universidade Brasil, Brasil \\ E-mail:doraineska@gmail.com
}

\begin{abstract}
Resumo
Algumas espécies de fungos são capazes de provocar infecções micóticas. Uma dessas infecções, é a dermatofitose, causada por um grupo de fungos, denominados Dermatófitos que compreende os gêneros Trichophyton, Microsporum e Epidermophyton. O tratamento da doença é realizada utilizando antifúngicos convencionais. A emergência de cepas resistentes tem estimulado ao desenvolvimento de medicamentos naturais e ao emprego do gás ozônio. Objetivou-se nesta pesquisa avaliar a atividade antifúngica de óleos essencias in natura e ozonizados frente ao Trichophyton mentagrophytes ATTC 9533. Foram empregados óleos essenciais in natura e ozonizados de Cinnamomum cassia, (L.) Presl), Eugenia caryphollata L. Merr. \& L. M. Perry, Cymbopogon winterianus Jowitt, Eucalyptus globulus Labill, Eucalyptus staigeriana F. Muell. ex F. M. Bailey e Mentha piperita L., avaliados quanto a atividade antifúngica. Os óleos foram ozonizados em equipamento corona (Ozon \& Life). Utilizou-se a técnica de microdiluição para avaliar a concentração inibitória mínima (CIM) e a concentração fungicida mínima (CFM). Foi determinada a cinética fungicida dos óleos essenciais. Os óleos de C. winterianus $C$. cassia e E. caryphollata, ozonizados se mostraram capazes de anular Trichophyton mentagrophytes com exposição de 5-10 minutos, mostrando-se mais eficientes que os de eucalipto e de menta De forma geral, os resultados evidenciaram a atividade antifúngica dos óleos essenciais, apontando a possibilidade do uso na terapêutica antifúngica frente ao dermatófito avaliado. No entanto há necessidade de realização de estudos em relação à segurança no uso e de eficácia dos óleos essenciais.
\end{abstract}

Palavras-chave: Dermatófito; Ozônio; Plantas medicinais; Antifúngico natural.

\begin{abstract}
Some species of fungi are capable of causing mycotic infections. One of these infections is dermatophytosis, caused by a group of fungi, called dermatophytes, which comprises the genera Trichophyton, Microsporum and Epidermophyton. The treatment of the disease is carried out using conventional antifungals. The emergence of resistant strains has stimulated the development of natural medicines and the use of ozone gas. The objective of this research was to evaluate the antifungal activity of essential oils in natura and ozonized against the Trichophyton mentagrophytes ATTC 9533. Essential oils in natura and ozonated from Cinnamomum cassia, (L.) Presl), Eugenia caryphollata L. Merr. \& L. M. Perry, Cymbopogon winterianus Jowitt, Eucalyptus globulus Labill, Eucalyptus staigeriana F. Muell. ex F. M. Bailey e Mentha piperita L. evaluated for antifungal activity. The oils were ozonized in corona equipment. The microdilution technique was used to assess the minimum inhibitory concentration (MIC) and the minimum fungicidal concentration (MFC). The fungicidal kinetics of essential oils were determined. $C$. winterianus $C$. cassia and E. caryphollata ozonated oils proved to be able to cancel Trichophyton mentagrophytes with exposure for 5-10 minutes, proving to be more efficient than those of eucalyptus and mint. In general, the results showed the antifungal activity of essential oils, pointing to the possibility of use in antifungal therapy against the
\end{abstract}


dermatophyte evaluated. However, there is a need for studies on the safety in use and the effectiveness of essential oils.

Keywords: Dermatophyte; Ozone; Medicinal plants; Natural antifungal.

\section{Resumen}

Algunas especies de hongos pueden causar infecciones micóticas. Una de estas infecciones es la dermatofitosis, causada por un grupo de hongos, denominados dermatofitos, que comprende los géneros Trichophyton, Microsporum y Epidermophyton. El tratamiento de la enfermedad se realiza mediante antifúngicos convencionales. La aparición de cepas resistentes ha estimulado el desarrollo de medicamentos naturales y el uso de gas ozono. El objetivo de esta investigación fue evaluar la actividad antifúngica de aceites esenciales in natura y ozonizados frente a Trichophyton mentagrophytes ATTC 9533. Aceites esenciales in natura y ozonizados de Cinnamomum cassia, (L.) Presl), Eugenia caryphollata L. Merr. \& L. M. Perry, Cymbopogon winterianus Jowitt, Eucalyptus globulus Labill, Eucalyptus staigeriana F. Muell. ex F. M. Bailey e Mentha piperita L.evaluados para actividad antifúngica. Los aceites se ozonizaron en un equipo corona. Se utilizó la técnica de microdilución para evaluar la concentración mínima inhibitoria (MIC) y la concentración mínima de fungicida (CFM). Se determinó la cinética fungicida de los aceites esenciales, los aceites de $C$. winterianus $C$. cassia y E. caryphollata ozonizados demostraron ser capaces de anular Trichophyton mentagrophytes con exposición de 5 a 10 minutos, demostrando ser más eficientes que los de eucalipto y menta. En general, los resultados mostraron la actividad antifúngica de los aceites esenciales, apuntando a la posibilidad de uso en terapia antifúngica contra el dermatofito evaluado. Sin embargo, es necesario realizar estudios sobre la seguridad en el uso y la eficacia de los aceites esenciales.

Palabras clave: Dermatofito; Ozono; Plantas medicinales; Antifúngico natural.

\section{Introdução}

Algumas espécies de fungos são capazes de provocar infecções, denominadas como micoses. A dermatofitóse é uma micose superficial que acomete as estruturas queratinizadas (pelos, unhas e pele) da pele. A doença é causada por um grupo de fungos, denominados dermatófitos classificados em três gêneros de fungos filamentosos: Trichophyton, Microsporum e Epidermophyton. (Menezes e Silva et al., 2006).

$\mathrm{Na}$ terapêutica dessas infecções são usados os agentes antifúngicos, que podem apresentar elevada toxicidade e/ou elevado custo (Khan et al., 2013), o que ocasiona uma busca por alternativas mais eficientes e com teor tóxico baixo para o tratamento das micoses, pelo uso de produtos de origem vegetal (Cortez et al., 2015).

$\mathrm{Na}$ medicina popular as plantas tem o uso simultâneo à utilização de medicamentos sintéticos, o que torna alta a procura por plantas medicinais e aromáticas em diversos países, devido à tendência dos consumidores a utilizarem, com preferência, os produtos farmacêuticos e os alimentícios de origem natural (Santos et al., 2011).

O conhecimento de uma possível atividade antifúngica dos óleos essenciais são de muita importância, pois abre possibilidades para a obtenção de futuros medicamentos antifúngicos de origem natural (Kumar et al., 2014; Cortez et al., 2015; Siddiqui et al., 2017, Batiha et al., 2020; Siham et al., 2020).

Vários estudos evidenciam a ação antimicrobiana dos óleos essenciais de capim-limão (Cymbopogon citratus (DC.) Stapf) (Guimarães et al., 2011), citronela (Cymbopogon nardus (L.) Rendle) (Medice et al., 2007), erva-cidreira (Lippia alba (Mill.) N.E. Br. ex Britton e P. Wilson) (Rozwalka et al., 2008) e menta (Mentha piperita L.) (Pereira et al., 2006) sobre o crescimento de fungos fitopatogênicos. A promissora atividade antimicrobiana dos óleos essenciais levou a usá-los em combinação com substâncias antimicrobianas para reduzir a toxicidade do fármaco, efeitos colaterais e resistência a agentes únicos (Tullio et al., 2019).

Devido a vários benefícios apresentados, a ozonioterapia é uma técnica que vem se destacando como uma opção para o tratamento para diferentes enfermidades, pois apresentam vantagens como baixo custo, a baixa invasividade, a ação antimicrobiana, fácil aplicação sistêmica ou local e a ausência de efeitos colaterais, intolerância ou contraindicações quando 
utilizada em doses terapêuticas. Este método vem sendo utilizado tanto na medicina humana e como na medicina veterinária (Bocci, 2006; Zanardi et al., 2016).

Estudos vem comprovando que os compostos presentes em óleos essenciais ozonizados são os responsáveis pela larga atividade biológica, assim como pelas atividades antimicrobianas e antifúngicas (Skalska et al., 2009, Bocci et al., 2009; Ouf et al., 2016; Kozusny-Andreani et al.; 2018; Carvalho et al., 2020, Ugazio et al.; 2020). Neste contexto, objetivou-se nesta pesquisa avaliar in vitro a atividade antifúngica dos óleos essenciais in natura e ozonizados de canela (Cinnamomum cassia), cravo-da-Índia (Eugenia caryphollata), citronela (Cymbopogon winterianus), eucalipto (Eucalyptus globulus, Eucalyptus staigeriana) e menta (Mentha piperita) frente a Trichophyton mentagrophytes ATTC 9533.

\section{Metodologia}

\section{Linhagens e meios de cultivo}

Para avaliar a atividade antimicrobiana dos óleos essenciais, foi utilizada a linhagem padrão: Trichophyton mentagrophytes ATTC 9533 (American Type Culture Collection, Figura 1). A qual foi reativada em meio de cultura agarizado Sabouraud-Dextrose (ASD, Kasvi ${ }^{\circledR}$ ) e o meio líquido caldo Sabouraud-Dextrose (CSD, Kasvi ${ }^{\circledR}$ ), preparados de acordo com as instruções do fabricante. Os meios foram solubilizados com água destilada e esterilizados em autoclave, a $121^{\circ} \mathrm{C}$ por 15 minutos.

A linhagem foi isolada (Figura 1) em placas de Petri contendo meio de cultura ASD estéril e incubadas de 5 a 7 dias a temperatura de $28^{\circ} \mathrm{C}$.

Figura 1: Cultura de Trichophyton mentagrophytes ATTC 9533 em meio Sabouraud-Dextrose

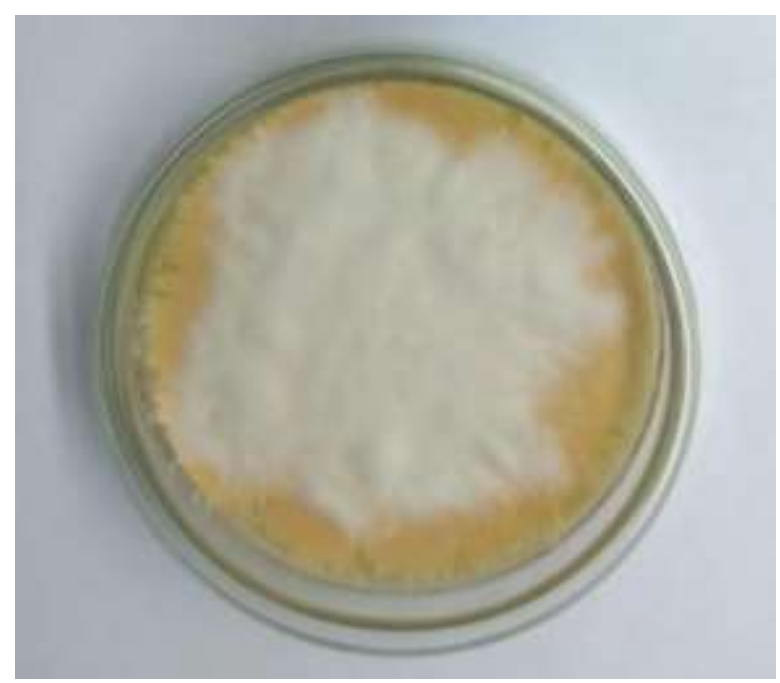

Fonte: Autores.

\section{Inóculo}

Para a preparação do inóculo, primeiramente, o fungo foi cultivado em meio CSD, submetido a agitação orbital constante $(225 \mathrm{rpm})$ e temperatura controlada $\left(28^{\circ} \mathrm{C}\right)$ por 5 dias. Foram preparadas suspensões do microrganismo em tubos solução salina estéril ( $\mathrm{NaCl}$ 0,5\%), as quais foram padronizadas segundo solução padrão do tubo 0,5 da escala McFarland, que corresponde a um inóculo de aproximadamente $10^{6}$ unidades formadoras de colônias $\mathrm{mL}^{-1}\left(\mathrm{UFC} \mathrm{mL}^{-1}\right)\left(\mathrm{Hadacek}_{\mathrm{C}} \mathrm{Greger}\right.$, 2000). 


\section{Óleos essenciais ozonizados}

Foram utilizados seis óleos essenciais sendo eles, canela (Cinnamomum cassia), cravo-da-Índia (Eugenia Caryphollata), citronela (Cymbopogon winterianus), eucalipto (Eucalyptus globulus, Eucalyptus staigeriana) e menta (Mentha piperita). Todos obtidos de indústria nacional (Ferquímica ${ }^{\circledR}$, localizada em, Vargem Grande Paulista, SP, Brasil

Para ozonizar os óleos essenciais, foi utilizado um aparelho gerador corona (Ozon \& Life) para a produção do gás ozônio e o oxigênio puro foi suprido via cilindro. O ozônio foi produzido de forma constante pelo equipamento e conduzido por um tubo de silicone para o difusor, pelo qual, os óleos foram expostos ao ozônio de forma direta por 30 minutos, em temperatura controlada de $25^{\circ} \mathrm{C}$. Todo o procedimento de ozonização foi conduzido em uma capela de exaustão da marca Quimis modelo 216.11, visando minimizar os riscos de aspiração do gás ozônio, seguindo as normas internacionais de segurança

Após ozonização, os óleos foram avaliados quanto a sua esterilidade. Foram então retirados $0,1 \mathrm{~mL}$ de cada óleo e inoculados em placas de Petri contendo meio ágar triptecaseina soja (TSA, Oxoid®), incubados a $37^{\circ} \mathrm{C}$ por $24 / 48$ horas, quando será verificado a ausência de crescimento microbiano. Será considerado estéril os óleos que não apresentarem nenhuma colônia. Os óleos essenciais ozonizados foram armazenados em frascos âmbar, identificados e mantidos sob refrigeração $8^{\circ} \mathrm{C}$.

\section{Determinação da Concentração inibitória mínima (CIM) e Concentração fungicida mínima (CFM)}

Todas as avaliações foram realizadas em caldo CSD suplementado com detergente Tween 20 (concentração final de $0,5 \%(\mathrm{v} / \mathrm{v})$. As linhagens dos microrganismos foram suspensas em caldo CSD para dar uma densidade final de $10^{6} \mathrm{CFU} \mathrm{mL}^{-1}$, e estas foram confirmadas por contagens de células viáveis.

A concentração inibitória mínima (CIM) e a concentração fungicida mínima (CFM) foram avaliadas de acordo o procedimento recomendado pelo Clinical and Laboratory Standards Institute (CLSI, 2008, 2012). A CIM foi determinada por um método de microdiluição em placas de 96 poços. O experimento foi conduzido empregando-se concentrações que variaram de 0,00 a $100 \%$ e os controles negativo e positivo. Todos os poços, receberam $0,05 \mathrm{~mL}$ de CSD, cada poço da segunda e quarta coluna recebeu $0,05 \mathrm{~mL}$ do óleo essencial. O conteúdo da quarta coluna, de forma a representar diluição $100 \%$, foi homogeneizado e $0,05 \mathrm{~mL}$ foram transferidos para o poço seguinte, representando a diluição $50 \%$. Estes procedimentos foram repetidos para as diluições $25 \%, 12,50 \%, 6,25 \%, 3,12 \%, 1,56 \%, 0,78 \%$ e $0,39 \%$. Por último foram, acrescentados $0,05 \mathrm{~mL}$ do inóculo $\left(10^{6}\right.$ células viáveis $\left.\mathrm{mL}^{-1}\right)$ de cada linhagem, com exceção dos controles negativo. A coluna 1 e 2 foram destinadas aos controles negativo e a coluna 3 para controle positivo.

Após incubação a $37^{\circ} \mathrm{C}$ por $24 \mathrm{~h}$, a CIM foi determinada pela adição de $50 \mu \mathrm{L}$ em cada amostra, do corante 2,3,5 Triphenyltetrazolium Chloride. Isto tornou possível distinguir as amostras vivas, coloridas de vermelho, daquelas mortas que mantiveram a sua cor. A concentração inibitória mínima foi considerada como a menor concentração de óleo essencial capaz de inibir o desenvolvimento bacteriano (Sylvester, 2011).

Para determinar a CFM, $20 \mu \mathrm{l}$ de amostras de todos os poços com inibição total do crescimento e do último poço com crescimento foram inoculados na superfície de placas de Petri com ágar Sabouraud-Dextrose. As placas foram incubadas a $28^{\circ} \mathrm{C}$ por 3 dias ou até o aparecimento das colônias fosse observado nas amostras controle. Os valores de CFM foram determinados como a concentração mais baixa de óleos essenciais, sem crescimento visível (Aiemsaard \& Punareewattana, 2017). 


\section{Cinética fungicida dos óleos essenciais}

Foi empregada a metodologia descrita por Allahghadri et al. (2010). Foram adicionados em tubos $40 \mu \mathrm{L}$ de cada óleo essencial na diluição determinada por CFM a cada $5 \mathrm{~mL}$ de caldo de CSD contendo suspensão fúngica de $10^{6}$ UFC mL-1 e foram em seguida incubados a $28^{\circ} \mathrm{C}$. Amostras $(0,1 \mathrm{~mL})$ foram retiradas nos tempos: 0', 5', 10', 20', 60', 120', 240', 480' e 24horas. As amostras foram espalhadas em cultura em agar Sabouraud Dextrose, incubadas durante $24 / 48 \mathrm{~h}$ a $28^{\circ} \mathrm{C}$. Todas as avaliações foram realizadas em triplicata.

As colónias microbianas foram contadas após o período de incubação. Foi realizada uma avaliação sobre a variação da carga microbiana a fim de observar qual óleo essencial apresentou a maior variação negativa (queda) na contagem microbiana. Nesse contexto, a variação percentual da contagem microbiana consistiu na seguinte relação:

\section{Contagem microbiana}

Essa relação foi empregada para todos os óleos essenciais avaliados

\section{Análise estatística}

Os dados foram avaliados através de análise descritiva da variação da contagem microbiana, conforme os tempos de exposição aos diferentes óleos essenciais. A abordagem dos dados de contagem microbiana, foi realizada, por meio de gráficos de linha, a fim de observar a evolução da variação da contagem microbiana com o tempo.

O Teste de Mann-Whitney foi utilizado para a comparação da variação da contagem microbiana em relação ao tratamento com ozônio.

Foi empregado o Teste de Kruskal-Wallis para a comparação da variação da contagem microbiana em relação aos óleos essenciais e ao tratamento de ozonização.

Todos os testes estatísticos foram aplicados com nível de significância de $5 \%$ (p<0,05).

Os Softwares utilizados foram Minitab 18 (Minitab Inc.) e MedCalc 14.8.1 (MedCalc Software Inc.).

\section{Resultados e discussão}

A espécie Trichophyton mentagrophytes pertence ao grupo dos dermatófitos, fungos filamentosos microscópicos que possuem afinidade pela queratina. Eles afetam a pele, as unhas ou o cabelo e causam lesões superficiais em humanos chamadas dermatofitose, que são as formas mais comuns de micose superficial no mundo (Tortora et al., 2017).

A dermatofitose é a principal causa de morbidade associada a micoses superficiais, com recidivas frequentes, muitas vezes refratárias à terapia (Madhavi et al., 2011). Na terapia antifúngica muitos medicamentos convencionais são usados, no entanto, o impacto da dermatofitose está aumentando no mundo. Dessa forma, a busca por novas alternativas terapêuticas para um melhor manejo desta doença se faz necessária (Havlickova et al., 2008; Youmsi Fokouo et al., 2020). Segundo Karpinski (2020) uma alternativa aos medicamentos convencionais pode ser os óleos essenciais, que possuem um amplo espectro antimicrobiano.

Com o intuito de avaliar a atividade antifúngica dos óleos essenciais, na presente pesquisa foram estimadas a concentração inibitória mínima (CIM) e concentração fungicida mínima (CFM) para os óleos essenciais de canela, citronela, cravo-da-Índia, citronela, eucalipto e menta in natura e ozonizados frente a Trichophyton mentagrophytes (Tabela 1). 
Verificou-se que os óleos de canela, cravo-da-Índia, citronela, eucalipto glouolus e eucalipto stageriana in natura apresentaram CIM e CFM que variaram entre $0,8 \%$ a $25 \%$, enquanto os óleos ozonizados de 0,8 a 3,1\%, evidenciando atividade antifúngica.

Tabela 1. Concentração inibitória mínima (CIM) e concentração fungicida mínima (CFM) para os óleos essenciais in natura e ozonizados frente a Trichophyton mentagrophytes.

\begin{tabular}{|c|c|c|c|c|c|}
\hline \multicolumn{2}{|r|}{ Óleo essencial } & \multicolumn{2}{|c|}{ CIM (\%) } & \multicolumn{2}{|c|}{ CFM (\%) } \\
\hline $\begin{array}{l}\text { Nome } \\
\text { popular }\end{array}$ & Nome científico & In natura & $\begin{array}{c}\text { Com } \\
\text { ozônio }\end{array}$ & In natura & $\begin{array}{c}\text { Com } \\
\text { ozônio }\end{array}$ \\
\hline Canela & Cinnamomum cassia & 6,2 & 0,8 & 3,1 & 0,8 \\
\hline Cravo & Syzygium aromaticum & 6,2 & 0,8 & 12,5 & 0,4 \\
\hline Citronela & Cymbopogon winterianus & 25 & 1,5 & 25 & 0,4 \\
\hline Menta & Mentha piperita & 0,8 & 0,8 & 0,8 & 0,8 \\
\hline Eucalipto & Eucalyptus globolus & 12,5 & 3,1 & 6,25 & 1,5 \\
\hline Eucalipto & Eucalyptus staigeriana & 12,5 & 1,5 & 3,1 & 0,8 \\
\hline
\end{tabular}

Fonte: Autores.

Os resultados das CFM, para maioria dos óleos, evidenciaram que o efeito do ozônio é significativo, uma vez que é necessário utilizar menor quantidade para o controle de Trichphyton mentagrophytes. Neste contexto, o uso do ozônio otimiza o combate ao fungo, auxiliando no controle da contaminação e, por conseguinte, diminuindo o tempo de desinfecção.

A Tabela 2 evidencia as estatísticas descritivas da variação global da carga microbiana do Tricophyton mentagrophytes ao longo dos períodos avaliados de acordo com os óleos essenciais e com o tratamento com ozônio. Verificouse que os óleos essenciais de citronela, de canela e de cravo-da-Índia foram os mais eficazes após o tratamento com ozônio $(n=3)$, indicando que houve uma ação do ozônio ao ser incorporado nos óleos, potencializando a ação antifúngica. Com relação ao Eucalyptus globulus ozonizado $(\mathrm{n}=12)$, não apresentou diferenças quando comparado com o óleo in natura, indicando que não houve diferenças quanto ao controle de Tricophyton mentagrophytes.

Tabela 2. Estatísticas descritivas da variação percentual (\%) global da contagem microbiana em relação aos óleos avaliados.

\begin{tabular}{lccccccc}
\hline \multirow{2}{*}{ Óleo essencial } & \multicolumn{3}{c}{ In natura } & \multicolumn{5}{c}{ Com ozônio } & \multirow{2}{*}{ Valor $\mathbf{p}^{\mathbf{1}}$} \\
\cline { 2 - 7 } Citronela & $\mathbf{N}$ & Média $\pm \mathbf{D P}^{2}$ & Mediana & $\mathbf{n}$ & Média $\pm \mathbf{D P}$ & Mediana & \\
Canela & 9 & $-58,2 \pm 45,0$ & $-80,0$ & 3 & $-99,7 \pm 0,00$ & $-99,7$ & 0,015 \\
Cravo-da-Índia & 6 & $-49,9 \pm 54,6$ & $-49,9$ & 3 & $-98,3 \pm 0,00$ & $-98,3$ & 1,000 \\
Eucalipto G & 12 & $-68,2 \pm 19,1$ & $-69,6$ & 12 & $-72,3 \pm 18,1$ & $-79,6$ & 0,839 \\
Eucalipto S & 15 & $-60,7 \pm 29,2$ & $-66,6$ & 12 & $-67,2 \pm 25,0$ & $-69,1$ & 0,509 \\
Menta & 15 & $-41,6 \pm 42,9$ & $-33,3$ & 9 & $-37,8 \pm 65,2$ & $-52,6$ & 0,810 \\
\hline
\end{tabular}

${ }^{1}$ Valor p referente ao teste de Mann-Whitney a p<0,05. ${ }^{2}$ DP: desvio padrão.

Fonte: Autores. 
Os resultados da Tabela 2 indicam a existência de diferenças significativas na média da variação microbiana global em dois óleos essenciais ozonizados: citronela ( $\mathrm{p}=0,015$, Figura 2) e cravo-da-Índia ( $\mathrm{p}=0,026$, Figura 3), evidenciando que o tratamento com ozônio surtiu efeito positivo e significativo na diminuição da carga fúngica. Nos demais óleos avaliados, o ozônio apresentou efeito positivo na redução de T. mentagrophytes, porém este efeito não foi significativo ( $\mathrm{p}>0,05)$.

Figura 2: Cultivo em ágar Sabouraud-Dextrose de Trichophyton mentagrophytes, após dez minutos de ação do óleo de citronela ozonizado (A) e óleo de citronela in natura $(\mathrm{B})$.

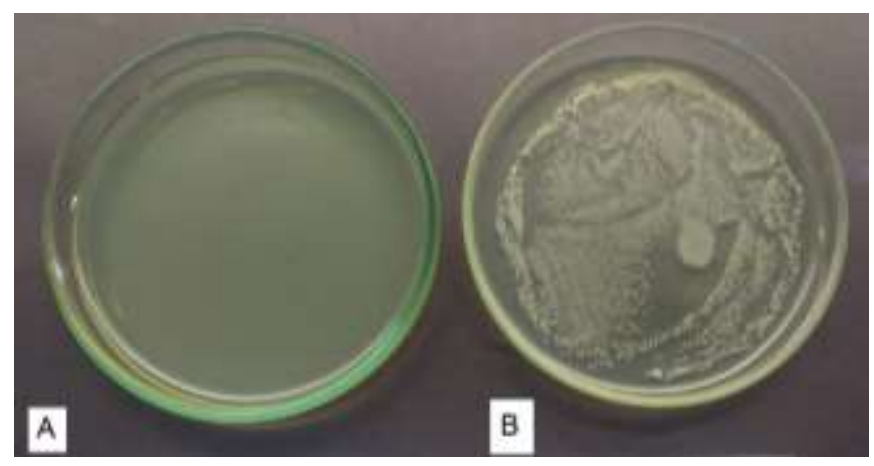

Fonte: Autores.

Figura 3: Cultivo em ágar Sabouraud-Dextrose de Trichophyton mentagrophytes após cinco minutos de ação do óleo de cravo-da-Índia ozonizado (A) e óleo-de cravo-da-Índia in natura (B).

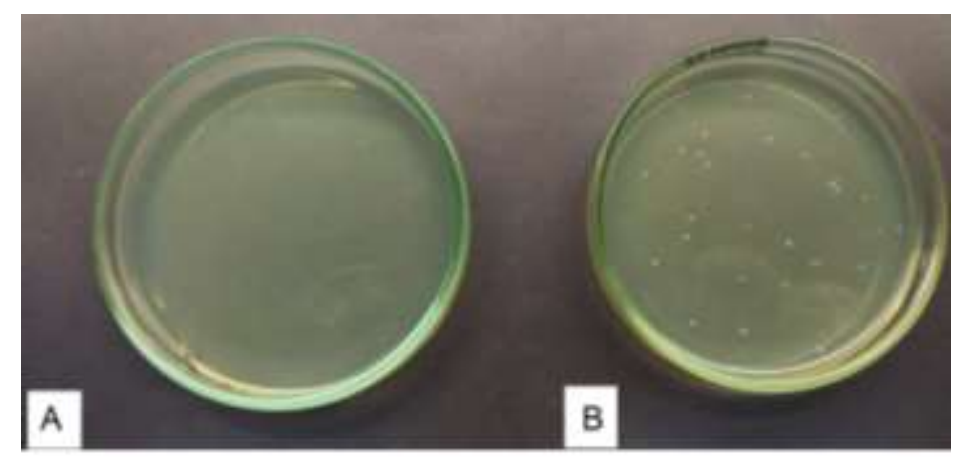

Fonte: Autores.

A eficácia do óleo de cravo-da-Índia no controle de T. mentagrphytes foi comprovada em pesquisa realizada por Park et al. (2007). Os resultados obtidos evidenciaram que as atividades antifúngicas contra dermatófitos foram elevadas, sendo necessários $0,2 \mathrm{mg} \mathrm{mL}^{-1}$ de óleo essencial para obter $60 \%$ de eficácia, inibindo completamente o crescimento de hifas.

Estudos de cromatografia gasosa-espectrometria de massa (GC-MS) do óleo essencial de cravo-da-Índia revelaram a presença de eugenol como composto principal. A análise fitoquímica mostrou a presença de saponinas, alcalóides, flavonóides, glicosídeos, taninos e esteróides (Kaur \& Kaushal, 2019). O eugenol é constituinte antifúngico mais eficaz do óleo de cravoda-Índia contra os dermatófitos, provocando alterações morfológicas como danos à parede e membrana celular e expansão do retículo endoplasmático, que foram observadas por microscopia eletrônica de transmissão (Park et al., 2007).

O óleo de cravo-da-Índia utilizado na presente pesquisa apresentou $86 \%$ de eugenol, e a ação antifúngica deste composto foi eficaz no controle de T. mentagrophytes, e provavelmente, a sua atividade foi aumentada com a ozonização, em vista que foi verificado que o tempo necessário para o controle do fungo foi de 5 minutos (Figura 3). De acordo com Siham et al. (2020) poder inibitório do crescimento de espécies de fungos e de bactérias resistentes evidenciou que Syzygium 
aromaticum (cravo-da-Índia) possui propriedades para ser considerada uma planta medicinal, e ser utilizada como fonte de compostos biológicos ativos podem ser uma alternativa eficaz aos antifúngicos convencionais.

As Figuras 4 e 5 evidenciam o comportamento das variações percentuais da contagem microbiana de cada um dos óleos essenciais utilizados nesta pesquisa. A discrepância na localização das medianas reitera a existência de diferenças estatísticas significativas, revelando que os tratamentos sem ozônio apresentaram maior dificuldade em diminuir a carga microbiana. Neste caso, os óleos ozonizados apresentam maior eficácia em auxiliar na diminuição da contaminação e otimizar o processo de desinfecção.

A atividade antifúngica do óleo de citronela sobre espécies de Aspergillus foi demostrada por Yousef (2013). Foi verificado no estudo realizado por este autor que o óleo de citronela indicou que o citral é o componente principal (70,17\%), com bioatividade sobre A. niger e A. fumigatus. O óleo essencial foi considerado altamente fungicida, pois apresentou os menores valores de MIC e CFM e a maior inibição de crescimento e foi eficaz na inibição da viabilidade fúngica e germinação de esporos. Ainda de acordo com este autor, os resultados mostraram que o óleo de citronela produz um efeito fungitóxico, o que apóia seu possível uso na medicina para terapéutica das infecções micóticas.

Figura 4: Variação percentual da contagem de Trichophyton mentagrophytes exposto ao óleo essencial de citronela in natura e ozonizado.

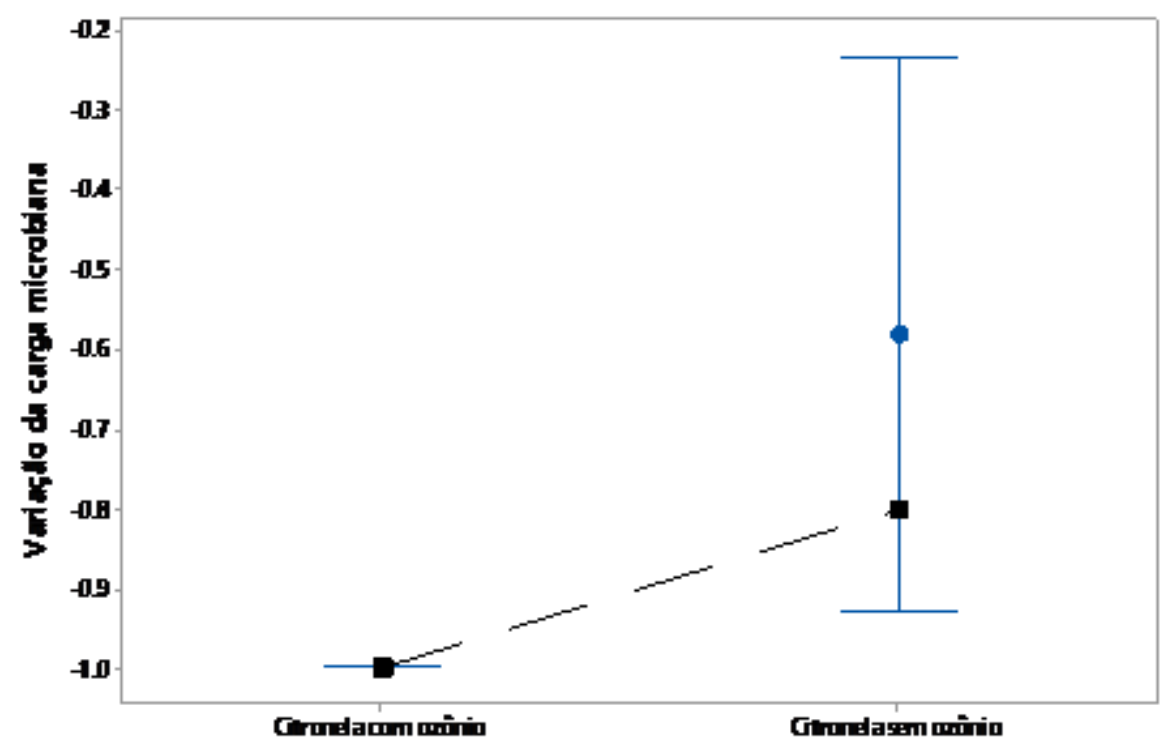

Nota: Pontos azuis referem-se à média e pontos pretos à mediana. Fonte: Autores. 
Figura 5: Variação percentual da contagem de Trichophyton mentagrophytes exposto ao óleo essencial de cravo-da-Índia in natura e ozonizado.

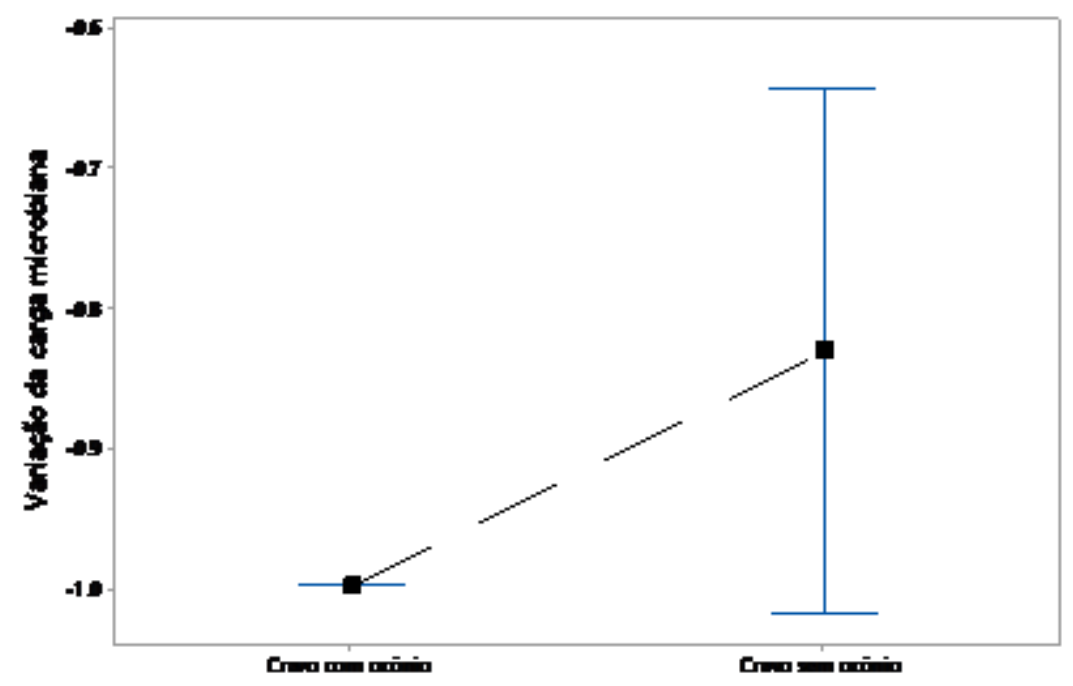

Nota: Pontos azuis referem-se à média e pontos pretos à mediana. Fonte: Autores.

Na Figura 6 são apresentados o comportamento da variação da carga microbiana do T. mentagrophytes em relação aos óleos essenciais estudados e uso do ozônio.

Os resultados obtidos com o óleo de citronela ozonizado revelaram efeito sinérgico, sendo capaz de zerar a carga microbiana no intervalo de tempo de 5 a 10 minutos, enquanto, o óleo in natura precisou de um tempo de ação maior (20 a 60 minutos), evidenciando diferenças estatísticas significativas.

Sinergismo foi observado, também com os óleos de canela e de cravo-da-Índia (Figura 6) ozonizados, evidenciando nulidade na contagem de T. mentagrophytes no intervalo de 5 a 10 minutos, enquanto que, os óleos in natura apresentaram um resultado nulo nos intervalos de tempo de 10 a 20 minutos.

Em relação aos óleos essenciais de eucalipto in natura e ozonizado, verificou-se atividade antifúngica semelhante em ambas as espécies, sendo necessário períodos de exposição mais prolongados. Os óleos de menta piperita in natura e ozonizado apresentaram grandes variações ao longo dos intervalos de tempo. Observou-se que o óleo ozonizado anulou a carga microbiana no intervalo de tempo de 20 a 60 minutos enquanto que o óleo in natura foi entre120 a 240 minutos (Figura 6 ).

Segundo Sabo \& Knezevic (2019) a aplicação na medicina tradicional do óleo essencial e extratos de eucalipto indica grandes propriedades antimicrobianas. Estes autores afirmam que o óleo essencial de Eucalyptus camaldulensis é mais ativo contra bactérias e fungos quando comparados com os de outras espécies do gênero Eucalyptus, em bactérias Gram negativas em concentrações de 0,01-3,2\%, e fungos de 0,125-1,0\%.

$\mathrm{Na}$ presente pesquisa os óleos de Eucalyptus globulus e E. staigeriana apresentaram eficácia em concentrações inibitória mínima (CIM) de 12,5\%, e fungicida mínima (CFM) de 6,25\% e 3,1\%, respectivamente. No entanto, quando estes óleos foram ozonizados apresentaram atividade antifúngica com CIM de 1,5\% e 3,1\% e CFM de 0,8\% e 1,5\% para os óleos de E. globulus e E. staigeriana, respectivamente (Tabela 1), evidenciando a ação sinérgica do ozônio.

A atividade antidermatofítica do óleo essencial de Mentha piperita foi observada por Ibrahim e El-Salam (2015) contra quatro fungos dermatófitos queratinofílicos (Microsporum canis, Epidermophyton floccosum, Trichophyton rubrum e Trichophyton mentagrophytes). Os resultados evidenciaram edicácia na concentração de 12,5\%. Estes resultados corroboram 
os obtidos na presente pesquisa, em vista que a atividade antifúngica foi verificada nas concentrações de $0,8 \%$ (Tabela 1 ), No entanto o tempo necessário para eliminar totalmente T. mentagrophytes foi no intervalo de 120 a 240 minutos para o óleo in natura e de 20 a 40 minutos para o óleo ozonizado, evidenciando a ação sinérgica do ozônio (Tabela 2, Figura 6).

A administração terapêutica do ozônio, conhecida como terapia de ozônio, surgiu como um possível tratamento para a reparação de tecidos, pois promove a cicatrização de feridas. Apresenta propriedades bactericidas, antivirais e antifúngicas e tem sido utilizado como recurso terapêutico no tratamento da inflamação e da infecção (Zanardi et al., 2008).

O ozônio via tópica na forma gasosa ou em óleos se destaca como tratamento para a reparação de tecidos, visto que promove a cicatrização de feridas e possui propriedades antimicrobianas, imunológicas, antioxidantes e oxigenantes. A eficácia do óleo ozonizado pode representar uma terapia integrativa no tratamento de lesões teciduais, principalmente em pacientes que apresentam patologias como diabetes mellitus, aterosclerose e no processo de envelhecimento. Para doenças como úlceras ou estomatite aftosa, gengivite e dermatite, o óleo ozonizado auxilia no alívio da dor e na aceleração do processo de cicatrização (De Almeida et al., 2012; Anzolin et al., 2020).

Segundo Moureu et al. (2016). o uso de óleos ozonizados como fármacos ou cosméticos requer informações sobre sua estabilidade ao longo do tempo. Estes autores destacam que a melhor forma de preservar a composição inicial do óleo ozonizado é mantendo em baixa temperatura. Este critério foi observado na presente pesquisa, sendo assim os óleos ozonizados foram mantidos sob refrigerção

Figura 6: Comportamento da variação da carga microbiana do Trichophyton mentagrophytes em relação aos óleos essenciais e uso do ozônio.
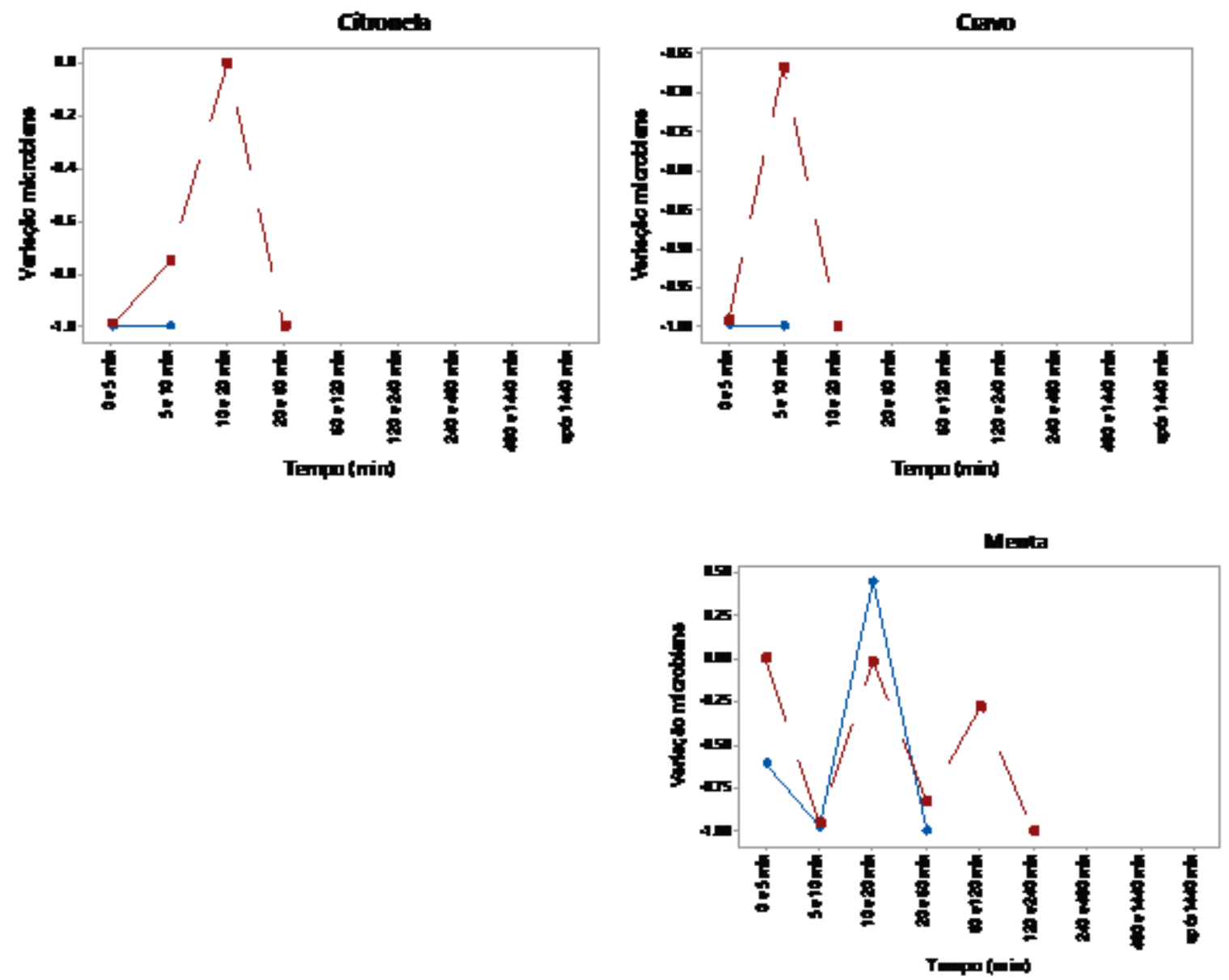

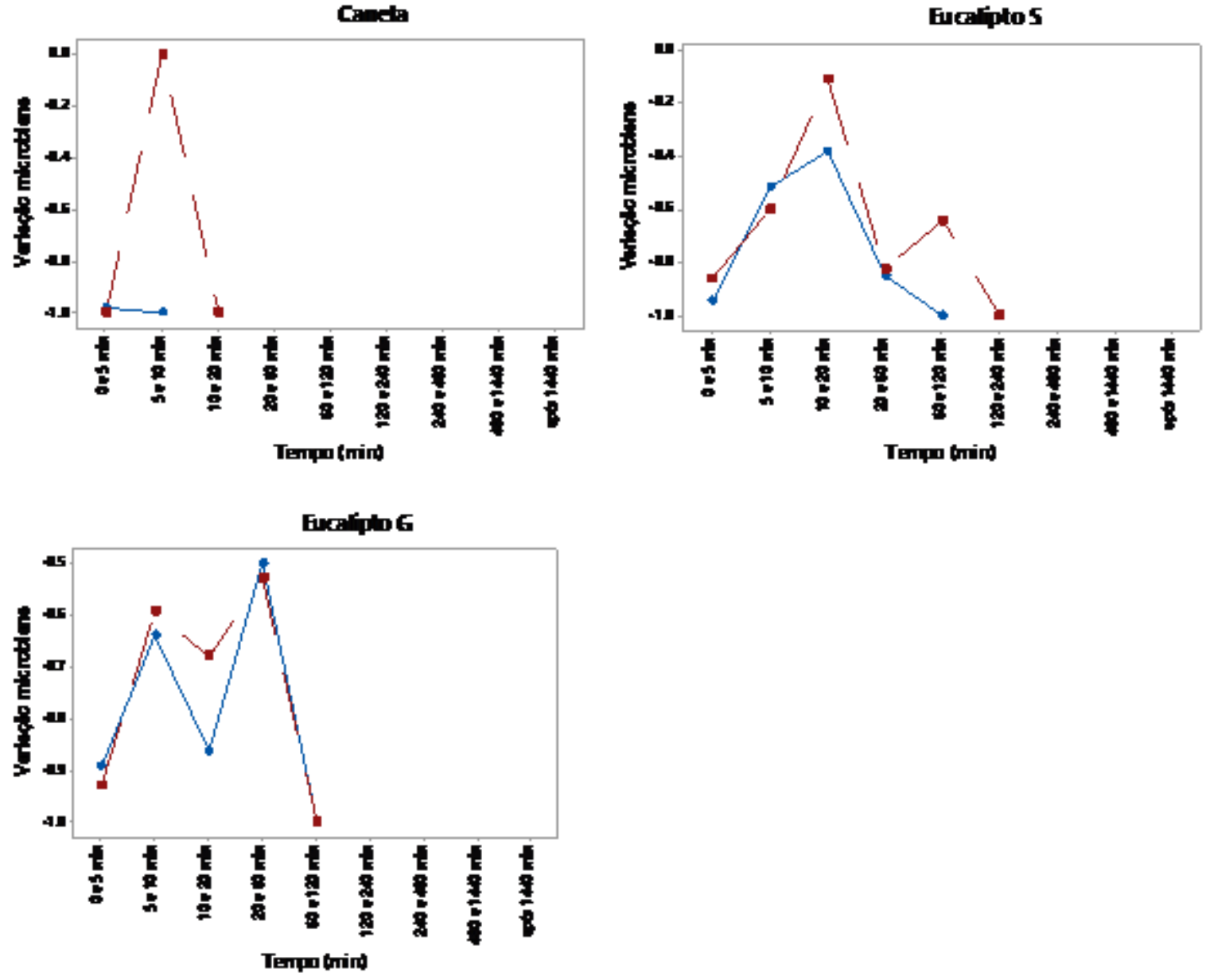

Fonte: Autores.

De acordo com Ugazio et al.(2020) a busca por um amplo espectro de agentes antimicrobianos que auxiliem a evitar a resistência dos microrganismos e ao mesmo tempo em que mantenham efeitos colaterais razoáveis, fez com que os óleos ozonizados experimentassem um aumento de interesse científico e das aplicações clínicas.

\section{Conclusão}

Os resultados obtidos nesta pesquisa evidenciaram de forma geral, que os óleos essenciais in natura e ozonizados apresentaram atividade antifúngica contra Trichophyton mentagrophytes. Pode-se verificar que o tratamento com ozônio produziu, para a maioria dos óleos, um efeito sinérgico potencializando assim sua ação antifúngica com relação ao microrganismo estudados, evidenciando que o tratamento de óleos essenciais com ozônio é promissor. Desta forma, fica evidente a possibilidade do uso dos óleos essenciais "in natura" e ozonizados na terapêutica antifúngica contra infecções causadas por Trichophyton mentagrophytes. 
Research, Society and Development, v. 10, n. 1, e4710111233, 2021

(CC BY 4.0) | ISSN 2525-3409 | DOI: http://dx.doi.org/10.33448/rsd-v10i1.11233

\section{Referências}

Aiemsaard, J., \& Punareewattana, K. (2017). Antifungal activities of essential oils of Syzygium aromaticum, Piper betle, and Ocimum sanctum against clinical isolates of canine Dermatophytes. Science Asia, 43(5), 223-228. 10.2306/scienceasia1513-1874.2017.43.223

Allahghadri, T., et al. (2010). Antimicrobial property, antioxidant capacity and cytotoxicity of essential oil from cumi.; produced in Iran. Journal of Food Science, 75(2), H54-H61, 2010.

Anzolin, A. P., et al. (2020). Ozonated oil in wound healing: what has already been proven? Medical Gas Research, 10(1), 54-59. 10.4103/2045-9912.279985

Batiha, G. E. S., et al. (2020). Syzygium aromaticum L. (Myrtaceae): Traditional Uses, Bioactive Chemical Constituents, Pharmacological and Toxicological Activities. Biomolecules, 10(202), 1-16. 10.3390/biom10020202

Bocci, V. A. (2006). Scientific and medical aspects of ozone therapy. State of the art. Archives of Medical Research, 37(4,), 425-435.

Bocci, V., et al. (2009). The ozone paradox: ozone is a strong oxidant as well as a medical drug. Medicinal Research Reviews, 29(4), 646-682. $10.1002 /$ med 20150

Carvalho, M. M. L., et al. (2020). Comparative analysis of in vitro antibacte.rial effectiveness of ozonized and non-ozonized vegetable oils on Neisseria gonorrhoeae. Journal of Modern Medicinal Chemistry, 8, 41-48. 10.12970/2308-8044.2020.08.05

Clinical and Laboratory Standards Institute. (2008). Reference Method for Broth Dilution Antifungal Susceptibility Testing of Filamentous Fungi; Approved Standard CLSI Document M38-A2; CLSI: Wayne, PA, USA.

Clinical and Laboratory Standards Institute. (2012). Reference Method for Broth Dilution Antifungal Susceptibility Testing of Yeasts; Fourth Informational Supplement; Document M27-S4; CLSI: Wayne, P. A., USA.

Cortez, L. E. R, et al. (2015). Avaliação da atividade antifúngica dos óleos essencias de Lippia alba (Mill.) NE Brown (Verbenaceae) e Cymbopogon citratus (DC) Stapf (Poaceae). Mundo saúde. 39(4), 433-440.

De Almeida, N. R., et al. (2012). Ozonized vegetable oils and therapeutic properties: A review. Orbital: The Electronic Journal of Chemistry, 4(4), 313-326. 10.17807/orbital.v4i4.467

Guimarães, L. G. D. L., et al. (2011). Atividades antioxidante e fungitóxica do óleo essencial de capim-limão e do citral. Revista Ciência Agronômica, 42(2), 464-472. 10.1590/S0100-29452014000500031

Hadacek, F., \& Greger, H. (2000) Testing of antifungal natural products: methodologies, comparability of results and assay choise. Phytochemical Analysis, 11(3), 137-147.

Havlickova, B., et al. (2008). Epidemiological trends in skin mycoses worldwide. Mycoses, 51(4), 2-15.

Ibrahim, S. Y., \& El-Salam, M. M. A. (2015). Anti-dermatophyte efficacy and environmental safety of some essential oils commercial and in vitro extracted pure and combined against four keratinophilic pathogenic fungi. Environmental Health and Preventive Medicine, 20, 279-286. 10.1007/s12199-015-0462-6

Kaur, K., \& Kaushal, S. (2019). Phytochemistry and pharmacological aspects of Syzygium aromaticum: A review. Journal of Pharmacognosy and Phytochemistry, 8(1), 398-406, www.phytojournal.com.

Khan, M. S. A, et al. (2013). Phenyl aldehyde and propano ids exert multiple sites of action towards cell membrane and cell wall targeting ergosterol in Candida albicans. AMB Express, 3(1), 54-61. 10.1186/2191-0855-3-54

Kozusny-Andreani, D. I., et al. (2018). In vitro,inactivation of pathogenic bacteria by the use of ozone in different exposure times. Revista Cubana de Medicina Tropical. 70, 34-44.

Kumar, V., et al. (2014). In vitro inhibition activity of essential oils from some Lamiaceae species against phytopathogenic fungi. Pesticide Biochemistry and Physiology, 114, 67-71. 10.1016/j.pestbp.2014.07.001

Madhavi, S., et al. (2011). Mycological study of dermatophytoses in rural population. Annals of Biological Research, 2, 88-93.

Medice, R., et al. (2007). Óleos essenciais no controle da ferrugem asiática da soja Phakopsora pachyrhizi syd. \& p. Syd. Ciência e Agrotecnologia, 31(1), 8390. 10.1590/S1413-70542007000100013.

Menezes e Silva, C. H. P., et al. (2006). Bacteriologia e Micologia para o Laboratório Clinico. Livraria e Editora Revinter Ltda.: Rio de Janeiro.

Moureu, S., et al. (2016). Influence of storage temperature on the composition and the antibacterial activity of ozonized sunflower oil. Ozone: Science \& Engineering, 38(2), 143-149. doi: 10.1080/01919512.2015.1128319.

Ouf, S. A., et al. (2016). Anti-fungal potential of ozone against some dermatophytes. Brazilian Journal of Microbiology, 47(3), 697-702. 10.1016/j.bjm.2016.04.014

Park, M. J., et al. 2007). Antifungal activities of the essential oils in Syzygium aromaticum (L.) Merr. Et Perry and Leptospermum petersonii Bailey and their constituents against various dermatophytes. Journal of Microbiology, 45(5), 460-465.

Pereira, M. C., et al. (2006). Inibição do desenvolvimento fúngico através da utilização de óleos essenciais de condimentos. Ciência e Agrotecnologia, 30(4), 731-738. 10.1590/S1413-70542006000400020. 
Research, Society and Development, v. 10, n. 1, e4710111233, 2021

(CC BY 4.0) | ISSN 2525-3409 | DOI: http://dx.doi.org/10.33448/rsd-v10i1.11233

Rozwalka, L. C., et al. (2008). Extratos, decoctos e óleos essenciais de plantas medicinais e aromáticas na inibição de Glomerella cingulata e Colletotrichum gloeosporioides de frutos de goiaba. Ciência Rural, 38(2), 301-307..org/10.1590/S0103-84782008000200001

Sabo, V. A., \& Knezevic, P. (2019). Antimicrobial activity of Eucalyptus camaldulensis Dehn. plant extracts and essential oils: A review. Industrial Crops and Products, 132, 413-429. 10.1016/j.indcrop.2019.02.051.

Siddiqui, S. A., et al. (2017). Chemical composition and antifungal properties of the essential oil and various extracts of Mikania scandens (L.) Willd. Arabian Journal Chemistry, 10(2), S2170-S2174. 10.1016/j.arabjc.2013.07.050.

Siham, Y., et al. (2020). Determination of chemical composition and evaluation of antioxidant, and antimicrobial activities of Clove oil obtained from Syzygium aromaticum Moroccan species. International Journal of Pharmaceutical Sciences and Research, 11(2), 2568-2574. 10.26452/ijrps.v11i2.2261.

Skalska, K., et al. (2009). Germicidal properties of ozonated sunflower oil. Ozone: Science \& Engineering, 31(3), 232-237. doi: 10.1080/01919510902838669.

Sylvester, P.W. (2011). Optimization of the tetrazolium dye (MTT) colorimetric assay for cellular growth and viability. Methods in Molecular Biology. 716, 157-168. 10.1007/978-1-61779-012-6_9.

Tortora, G. J., Funke, B. R., \& Case, C. L. (2017). Microbiologia. (12a ed) Artmed, 939.

Tullio, V., et al. (2019). Evaluation of the Antifungal Activity of Mentha x piperita (Lamiaceae) of Pancalieri (Turin, Italy) Essential Oil and Its Synergistic Interaction with Azoles. Molecules. 24, 3148. 10.3390/molecules24173148.

Ugazio, E., et al. (2020). Ozonated oils as antimicrobial systems in topical applications. their characterization, current applications, and advances in improved delivery techniques. Molecules. 25, 334. 10.3390/molecules25020334.

Youmsi Fokouo, R. D., et al. (2020). Antidermatophyte activity of Syzygium aromaticum, Petroselinum crispum, and Tetrapleura tetraptera. Biomedical and Biotechnology Research Journal. 4, 55-60. http://www.bmbtrj.org.

Yousef, S. A. A. (2013). Antifungal Activity of Volatiles from Lemongrass (Cymbopogon citratus) and Peppermint (Mentha piperita) Oils Against Some Respiratory Pathogenic Species of Aspergillus. International Journal of Current Microbiology and Applied Sciences, 2(6), 261-272. http://www.ijcmas.com.

Zanardi, I., et al. (2008). Physico-chemical characterization of sesame oil derivatives. Lipids, 43, 877-886. doi:10.1007/s11745-008-3218-x.

Zanardi, I., et al. (2016). Ozone: a multifaceted molecule with unexpected therapeutic activity. Current Medicinal Chemistry 23(4), 304-314 $10.2174 / 0929867323666151221150420$. 